\title{
RISCO CLIMÁTICO DE QUEBRA DE PRODUTIVIDADE DA CULTURA DO FEIJOEIRO EM SANTO ANTÔNIO DE GOIÁS, GO(1)
}

\author{
ELZA JACQUELINE LEITE MEIRELES ${ }^{(2)}$; ANTONIO ROBERTO PEREIRA ${ }^{(3,5)}$; \\ PAULO CESAR SENTELHAS ${ }^{(3)}$; LUIS FERNANDO STONE ${ }^{(4,5)}$; \\ FRANCISCO JOSÉ PFEILSTICKER ZIMMERMANN ${ }^{(4)}$
}

\begin{abstract}
RESUMO
A caracterização de riscos climáticos para algumas culturas tem sido feita com modelos de simulação e para a cultura do feijoeiro (Phaseolus vulgaris L.) tem-se utilizado o CROPGRO-Dry Bean. Esse modelo calibrado e testado para a região de Santo Antônio de Goiás, GO, foi utilizado na análise de risco climático de quebra relativa de produtividade da cultura naquela região. Para as simulações utilizou-se a série de dados climatológicos (1978 a 1998), as características físicas, químicas e hídricas do solo local (Latossolo Vermelho perférrico), e o módulo "seasonal" do DSSAT 3.5. Foram feitas simulações para a região, a fim de se obter as produtividades potencial ( $Y p$, sem restrição de água no solo) e real (Yr, com restrição dependente das chuvas) da cultivar Carioca. A quebra de rendimento, definida por $\mathrm{Q}(\%)=[1$ - (Yr/Yp)].100, foi calculada para cada uma das 36 épocas de semeadura simuladas ao longo do ano, nos 21 anos avaliados, sendo convertidas em freqüência relativa para análise dos resultados. Obteve-se Q > 50\% na semeadura da "seca"; Q = 34\%, em média, na semeadura das "águas"; e Q > 95\%, na semeadura de "inverno". Esses resultados enfatizam a necessidade de irrigação suplementar nas semeaduras da "seca" e das "águas", e durante todo o ciclo, nas semeaduras de "inverno".
\end{abstract}

Palavras-chave: feijão comum, modelo CROPGRO-Dry Bean, quebra de rendimento.

\section{ABSTRACT \\ YIELD DECREASE IMPOSED BY CLIMATIC HAZARDS TO THE DRY BEAN CROP IN SANTO ANTÔNIO DE GOIÁS, GOIÁS STATE, BRAZIL}

Characterization of climatic hazards for some crops has been carried out using simulation models, and for the dry bean crop (Phaseolus vulgaris L.) one that has been used is the CROPGRO-Dry Bean. Such model calibrated and tested for Santo Antônio de Goiás, Goiás State, Brazil, was used to detect relative bean yield losses imposed by the climate in that region. Simulations were performed using the climatological series (1978 to 1998), the soil physical, chemical and hydric characteristics (Oxisol), and the DSSAT 3.5 system seasonal module. Simulations were made to obtain the potential (Yp, without soil

( $\left.{ }^{1}\right)$ Extraído da Tese de Doutorado da primeira autora apresentada à Escola Superior de Agricultura "Luiz de Queiroz/USP. Recebido para publicação em 13 de junho de 2002 e aceito em 6 de janeiro de 2003.

$\left(^{2}\right)$ Embrapa Café, PqEB - Av. W3 Norte (Final) - Edifício Sede da Embrapa, 3. ${ }^{\circ}$ andar, 70770-901 Brasília (DF). E-mail: jacqueline.meireles@embrapa.br

$\left({ }^{3}\right)$ Departamento de Ciências Exatas, ESALQ-USP,Caixa Postal 9, 13418-900 Piracicaba (SP). E-mail:arpereir@carpa.ciagri.usp.br ; pcsentel@carpa.ciagri.usp.br

$\left({ }^{4}\right)$ Embrapa Arroz e Feijão, Caixa Postal 179, 75375-000 Santo Antônio de Goiás (GO). E-mail: stone@cnpaf.embrapa.br ; fjpz@cnpaf.embrapa.br

$\left({ }^{5}\right)$ Com bolsa de produtividade científica do CNPq. 
water deficit) and actual (Yr, soil water deficit dependent on rainfall) yields for the cultivar Carioca. Percent yield loss, defined as $\mathrm{Q}(\%)=[1-(\mathrm{Yr} / \mathrm{Yp})] .100$, was calculated for each of the 36 sowing dates simulated along the year, for the 21 years evaluated, and expressed as relative distribution frequency. Results revealed $Q>50 \%$ for the "dry" season; on average $Q=34 \%$ for the "wet" season; and $Q>95 \%$ for the "winter" season. It is clear that supplementary irrigation was necessary in the first two sowing seasons, and during the entire crop cycle during the winter season.

Key words: common bean; CROPGRO - Dry Bean model; yield decrease.

\section{INTRODUÇÃO}

No Estado de Goiás, as épocas de semeadura recomendadas para a cultura do feijoeiro concentramse em três períodos: "águas" (outubro a novembro); "seca" (janeiro a fevereiro) e "inverno" (maio a junho) (EMBRAPA,1994). A semeadura "das águas" apresenta um inconveniente - o risco de ocorrência de chuvas no período da colheita, que pode comprometer a produção. Na semeadura "da seca", o risco da falta ou distribuição irregular das chuvas é maior, afetando sensivelmente o rendimento. O feijão "de inverno", cultivado no período seco, sob irrigação, vem atraindo médios e grandes produtores, geralmente, usuários de melhor tecnologia.

Segundo dados do IBGE (1991, 1992, 1993, 1994, 1995, 1996, 1997, 1998, 1999, 2000), a área cultivada, a produção e o rendimento do feijão em Goiás oscilaram bastante nessas três safras no período de 1991 a 2000. Esse fato pode estar relacionado ao alto risco que esta cultura está exposta, devido a sua sensibilidade às condições climáticas e ao ataque de pragas e doenças. Portanto, é necessário que se caracterize os riscos climáticos envolvendo a cultura do feijoeiro no Estado.

A caracterização de riscos climáticos tem sido feita para algumas culturas, tais como: arroz de sequeiro (Meireles et al., 1995; Silva et al., 1997), feijão (MEIRELES et al.,1997a,b; SILVA et al., 1999; WREGE et al., 1997), milho (SANs et al., 1997), soja (FARIAs et al., 1997) e girassol (MARIN et al., 2000; Rolim, 2000), em vários Estados brasileiros, utilizando-se modelos de simulação.

Tais modelos são ferramentas de grande potencial na análise probabilística de riscos climáticos de quebra de produção, e podem ser também integrados a um sistema de informação geográfica para espacialização de seus resultados, enfatizando-se a análise econômica.

Uma das maneiras de se avaliar esse risco é por meio de modelos de simulação para desenvolvimento e crescimento do feijoeiro, dentre eles, o modelo CROPGRO-Dry Bean, versão 2.02, pertencente ao sistema DSSAT (Decision Support System for Agrotechnology Transfer). Trata-se de uma ferramenta que integrando dados do clima, do solo e da cultura, resultam informações sobre os melhores períodos para semeadura, nos quais a cultura provavelmente sofrerá menor quebra de produtividade.
Dentre os estudos já realizados utilizando-se o CROPGRO-Dry Bean, destacam-se: avaliação de diferentes estratégias de manejo de irrigação visando ao melhor benefício econômico para a cultura do feijoeiro no Estado do Paraná (FARIA et al., 1997a); calibração do modelo BEANGRO para o feijoeiro nas condições de Londrina, PR, com intuito de testar sua performance em simular a fenologia, produção de matéria seca e grãos desta cultura sob diferentes condições ambientais (FARIA et al., 1997b); determinação das épocas de semeadura com menores riscos para a cultura do feijoeiro, em condições de sequeiro e irrigada, em Santo Antônio de Goiás (GO), utilizando as produtividades potencial e real, e a quebra relativa de produtividade simulada pelo CROPGRO-Dry Bean (Meireles, 2000 e Meireles et al., 2001); determinação da necessidade de irrigação pela cultura do feijoeiro no nordeste da Bacia do Rio Tibagi, no Estado do Paraná, utilizando-se o CROPGRO-Dry Bean associado a um sistema de informações geográficas para regionalizar as informações (HEINEMANN e HoOgenBoOm, 2001).

Este trabalho objetivou determinar as épocas de semeadura com menores riscos climáticos de quebra de produtividade da cultivar de feijão Carioca, para Santo Antônio de Goiás, GO, utilizando simulações de longo período com o CROPGRO - Dry Bean.

\section{MATERIAL E MÉTODOS}

O modelo CROPGRO-Dry Bean calcula o balanço hídrico no solo para cada uma das camadas do perfil, utilizando o modelo unidimensional desenvolvido por RITCHIE (1985) que determina a redistribuição de água devido à irrigação, precipitação e drenagem, e estima a evapotranspiração potencial, a evaporação do solo e a transpiração da planta.

Nesse modelo, o perfil de solo é preenchido por água, camada por camada, até que se atinja o conteúdo correspondente à capacidade de campo nessas camadas, sendo o excesso contabilizado como drenagem profunda ou escoamento superficial. 
A infiltração da água de chuva ou da irrigação e o escoamento superficial são estimados pela modificação do método do número da curva de escoamento superficial SCS - "Soil Conservation Service".

A evapotranspiração potencial pode ser estimada pelos métodos de Priestley-Taylor ou Penman - FAO. Nesse estudo, utilizou-se o método de Priestley-Taylor, que necessita apenas dos dados de temperatura máxima e mínima do ar e saldo de radiação.

A evapotranspiração é dividida em transpiração da planta e evaporação do solo. A transpiração é proporcional à energia interceptada pelo dossel da cultura e a evaporação do solo depende da quantidade de energia que atinge a superfície do solo, sendo afetadas por índice de área foliar, albedo do solo, e teor de água no solo (FARIA et al., 1997a).

Ressalta-se que o CROPGRO-Dry Bean possui várias sub-rotinas para o cálculo do balanço hídrico no perfil de solo, englobando muitas equações que não serão apresentadas neste trabalho, porém podem ser encontradas bem detalhadas em PORTER et al. (1998).

Para a execução do modelo CROPGRO-Dry Bean, versão 2.02, desenvolvido por HoogenboOm et al. (1994), é necessário conhecer-se os parâmetros genéticos da cultivar, do solo, de manejo e dos elementos climáticos. São três arquivos que caracterizam os dados de entrada referentes à planta, conforme a seguinte descrição: (a) arquivo.ECO, caracteriza o ecótipo, contendo atributos genéticos que diferenciam cultivares de crescimento determinado e indeterminado; (b) arquivo. SPE, caracteriza a espécie, contendo coeficientes que definem a composição básica dos tecidos e descrevem os processos de fotossíntese, respiração, assimilação de nitrogênio, partição de fotoassimilados, senescência, fenologia e crescimento; (c) arquivo. CUL, contém informações da cultivar, tais como, sensibilidade ao fotoperíodo, taxa fotossintética, área foliar específica, massa máxima de um grão, área máxima de um trifólio, número médio de grãos por vagem, períodos entre emergência e $1 .^{\mathrm{a}}$ flor, $1 .^{a}$ flor e $1 .^{\mathrm{a}}$ vagem, $1 .^{\mathrm{a}}$ flor e $1 .^{\mathrm{o}}$ grão, $1 .^{\mathrm{o}}$ grão e maturação fisiológica, $1 .^{a}$ flor e o fim da expansão foliar.

Os elementos climáticos, temperatura máxima e mínima do ar, precipitação pluvial e insolação, base diária, foram armazenados nos arquivos de clima (ESTAÇÃO.WTH e ESTAÇÃO.CLI).

Os dados de solo, como por exemplo, densidade global, umidade de saturação, umidade à capacidade de campo, umidade no ponto de murcha permanente, albedo do solo, análise granulométrica, carbono orgânico, textura, $\mathrm{pH}$ em água, dentre outros, foram armazenados no arquivo SOIL.SOL.
Os dados de manejo da cultura (irrigação, fertilizantes, incorporação de resíduos e rotação de culturas, dados de semeadura) foram definidos no arquivo $X$.

Para a realização deste trabalho, utilizou-se a série climatológica (1978 a 1998) de valores diários de temperatura máxima e mínima do ar, precipitação pluvial e número de horas de insolação, obtidos da estação climatológica da Embrapa - Centro Nacional de Pesquisa de Arroz e Feijão, localizada em Santo Antônio de Goiás, GO (16 $\left.28^{\prime} \mathrm{S} ; 4^{\circ} 17^{\prime} \mathrm{W} ; 823 \mathrm{~m}\right)$, e também, as características físicas, químicas e hídricas do solo do local, classificado como Latossolo Vermelho perférrico para gerar os arquivos de clima e solo a serem usados nas simulações.

Anteriormente, esse modelo foi previamente calibrado e testado para a região de Santo Antônio de Goiás (Meireles, 2000), utilizando-se dados de fenologia, produtividade de grãos, e componentes de produção da cultivar de feijão Carioca obtidos por StONe e Pereira (1994a,b) em um experimento em campo, irrigado por aspersão, via pivô central.

Para a análise de risco climático de quebra relativa de produtividade da cultura foram efetuadas simulações de longo período (1978-1998), utilizandose o módulo "seasonal" do sistema DSSAT 3.5.

Foram feitas simulações para a região, a fim de se obter a produtividade potencial (Yp) sem restrição de água no solo (com irrigação), e a produtividade real (Yr) da cultura, com o déficit natural de água no solo dependente da precipitação pluvial.

Simularam-se 36 épocas anuais de semeaduras, sempre no primeiro dia de cada decêndio $\left(1 .^{\circ} / 1\right.$; $11 / 1 ; 21 / 1 ; 1 .^{\circ} / 2$ até $21 / 12$ ) ao longo dos 21 anos de dados climáticos disponíveis. Utilizou-se a cultivar Carioca em espaçamento de 0,60 m, com densidade populacional de 32,5 plantas. $\mathrm{m}^{-2}$, profundidade de semeadura de $0,05 \mathrm{~m}$, dose de adubação de $500 \mathrm{~kg} \cdot \mathrm{ha}^{-1}$ da fórmula 4-30-16 de N-P-K, correspondendo a aplicações de $20 \mathrm{~kg} \cdot \mathrm{ha}^{-1}$ de $\mathrm{N}, 150 \mathrm{~kg} \cdot \mathrm{ha}^{-1}$ de $\mathrm{P}_{2} \mathrm{O}_{5}$ e 80 kg.ha ${ }^{-1}$ de $\mathrm{K}_{2} \mathrm{O}$, na semeadura, seguidas de 30 kg.ha ${ }^{-1}$ de $\mathrm{N}$, em cobertura, aos 30 dias após a semeadura.

Para cálculo da produtividade potencial (Yp, $\left.\mathrm{kg} . \mathrm{ha}^{-1}\right)$, em cada época de semeadura, foram consideradas as condições não limitantes de água e nutrientes, e sem ataques de pragas ou doenças.

No caso da produtividade real $\left(\mathrm{Yr}, \mathrm{kg} \cdot \mathrm{ha}^{-1}\right)$, o suprimento de água foi aquele imposto pela chuva, dependente das condições climáticas da região, sendo adotada a mesma adubação mencionada anteriormente, descartando-se também possíveis ataques de pragas e moléstias. 
A análise das simulações foi feita por médias, desvios-padrão e coeficientes de variação, nas diferentes datas de semeaduras, nos 21 anos considerados. A quebra de rendimento $(\mathrm{Q}$, em $\%)$ foi determinada para cada época de semeadura simulada, nos anos avaliados, ou seja,

$$
Q=\left(1-\frac{Y r}{Y p}\right) 100
$$

posteriormente convertida em freqüência relativa para análise conjunta dos resultados

\section{RESULTADOS E DISCUSSÃO}

A produtividade potencial ( $\mathrm{Yp}$ ) simulada (Quadro 1) variou entre 2.787 e 3.752 kg.ha ${ }^{-1}$. Cada valor no quadro 1 representa a média de 21 simula- ções. A maior Yp alcançada foi para a semeadura em $1 .^{\circ} / 5$, cuja maturação fisiológica foi atingida aos 83 dias após semeadura (DAS), ou seja, em torno de 23/ 7. As condições climáticas no período de maio a julho foram caracterizadas por temperatura média mensal de $22,2{ }^{\circ} \mathrm{C}$; precipitação pluvial total de 54,3 $\mathrm{mm}$; e radiação solar global média de $17,5 \mathrm{MJ} \mathrm{m}^{-2} . \mathrm{d}^{-1}$, correspondendo às condições de aptidão plena para o cultivo do feijoeiro, descritas por FANCELLI e DouRADO Neto (1999). Dados do IBGE (1999) indicam que é possível obter-se produtividade acima de 2.400 kg.ha ${ }^{-1}$ em Goiás quando a semeadura de outono/inverno é desenvolvida sob irrigação.

Yp simulada abaixo de $3.000 \mathrm{~kg}$.ha ${ }^{-1}$ foi obtida para as semeaduras entre $1 .^{\circ} / 9$ e $21 / 11$. A menor delas ocorreu para a semeadura de 11/10, atingindo a maturação fisiológica aos 76 DAS (em 26/12), coincidindo com o período chuvoso na região, fato que pode ter provocado a queda da produção de grãos, devido ao aumento da nebulosidade e à conseqüente redução da radiação solar.

Quadro 1. Produtividades potenciais médias e desvios padrões médios (DP) simulados, pelo modelo CROPGRO - Dry Bean, e coeficientes de variação (CV), para a cultura do feijoeiro, cultivar Carioca, espaçamento de 0,60 m, em Santo Antônio de Goiás, GO. Período de 1978 a 1998

\begin{tabular}{|c|c|c|c|c|c|c|c|}
\hline \multirow{2}{*}{ Semeadura } & \multicolumn{7}{|c|}{ Produtividade potencial $\left(\mathrm{kg} \cdot \mathrm{ha}^{-1}\right)$} \\
\hline & Média & $\mathrm{DP}$ & $\mathrm{CV}$ & Semeadura & Média & $\mathrm{DP}$ & $\mathrm{CV}$ \\
\hline & & & $\%$ & & & & $\%$ \\
\hline 1. ${ }^{\circ} / 01$ & 3.270 & 279 & 8,6 & $1 .^{\circ} / 07$ & 3.358 & 262 & 7,8 \\
\hline $11 / 01$ & 3.293 & 271 & 8,2 & $11 / 07$ & 3.341 & 265 & 7,9 \\
\hline $21 / 01$ & 3.232 & 262 & 8,1 & $21 / 07$ & 3.392 & 263 & 7,8 \\
\hline 1. ${ }^{\circ} / 02$ & 3.318 & 250 & 7,5 & $1 .^{\circ} / 08$ & 3.167 & 302 & 9,5 \\
\hline $11 / 02$ & 3.348 & 285 & 8,5 & $11 / 08$ & 3.103 & 221 & 7,1 \\
\hline $21 / 02$ & 3.256 & 255 & 7,8 & $21 / 08$ & 3.032 & 262 & 8,6 \\
\hline $1 .^{\circ} / 03$ & 3.302 & 268 & 8,1 & $1 . \% / 09$ & 2.984 & 224 & 7,5 \\
\hline $11 / 03$ & 3.287 & 312 & 9,5 & $11 / 09$ & 2.870 & 256 & 8,9 \\
\hline $21 / 03$ & 3.481 & 267 & 7,7 & $21 / 09$ & 2.888 & 270 & 9,3 \\
\hline $1 .^{\circ} / 04$ & 3.541 & 304 & 8,6 & $1 .^{\circ} / 10$ & 2.896 & 236 & 8,1 \\
\hline $11 / 04$ & 3.693 & 258 & 7,0 & $11 / 10$ & 2.787 & 204 & 7,3 \\
\hline $21 / 04$ & 3.723 & 206 & 5,6 & $21 / 10$ & 2.849 & 260 & 9,1 \\
\hline $1 .^{\circ} / 05$ & 3.752 & 278 & 7,4 & $1 .^{\circ} / 11$ & 2.954 & 276 & 9,4 \\
\hline $11 / 05$ & 3.690 & 231 & 6,3 & $11 / 11$ & 2.871 & 229 & 8,0 \\
\hline $21 / 05$ & 3.606 & 309 & 8,6 & $21 / 11$ & 2.938 & 254 & 8,6 \\
\hline $1 .^{\circ} / 06$ & 3.603 & 353 & 9,8 & $1 .^{\circ} / 12$ & 3.072 & 285 & 9,3 \\
\hline $11 / 06$ & 3.360 & 254 & 7,6 & $11 / 12$ & 3.076 & 256 & 8,3 \\
\hline $21 / 06$ & 3.324 & 297 & 8,9 & $21 / 12$ & 3.034 & 268 & 8,8 \\
\hline
\end{tabular}


A distribuição da freqüência relativa de $\mathrm{Yp}$ mostra simetria com valores entre 2.000 e 4.500 kg.ha ${ }^{-1}$, e maior freqüência entre 3.000 e 3.500 kg.ha ${ }^{-1}$ (Figura 1). Os valores simulados foram sempre inferiores ao intervalo de 4.000 a $6.000 \mathrm{~kg} . \mathrm{ha}^{-1}$ relatado por WHITE e IZQUIERDO (1991) como indicativo da produtividade potencial do feijoeiro. Alto rendimento é obtido em parcelas experimentais e em condições ambientais favoráveis ao desenvolvimento da cultura (solo fértil, alta radiação, temperatura noturna amena de 10 a $13{ }^{\circ} \mathrm{C}$ e baixa incidência de pragas e doenças). SiLva e BARbosa Filho (2000) e Quintela (2000) verificaram que produtividade acima de $4000 \mathrm{~kg}$.ha ${ }^{-1}$ é possível em sistema de plantio direto, na região dos cerrados. Portanto, os valores aqui simulados podem ser interpretados como bons descritores das restrições térmicas e de radiação solar da região para a cultura do feijoeiro.

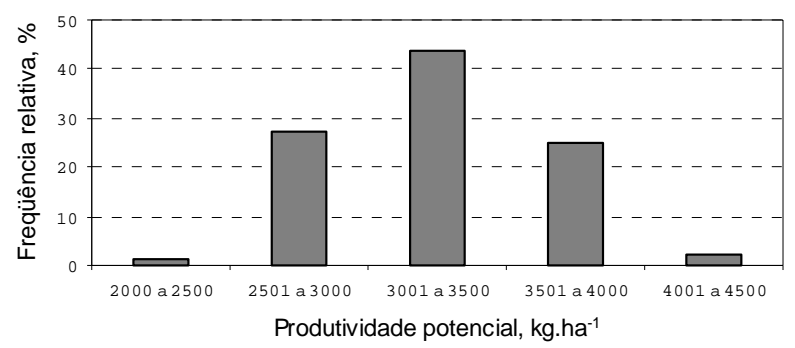

Figura 1. Distribuição de freqüência relativa da produtividade potencial média simulada pelo modelo CROPGRO - Dry Bean, para a cultura do feijoeiro, cultivar Carioca, nas 36 datas de semeadura analisadas, em Santo Antônio de Goiás (GO). Período de 1978 a 1998.

Quanto ao desvio-padrão de Yp, o menor valor verificado foi em torno de $204 \mathrm{~kg}$. ha ${ }^{-1}$ para semeadura em 11/10, enquanto o maior, $354 \mathrm{~kg} . \mathrm{ha}^{-1}$ para semeadura em $1 .^{\circ} / 6$.

O coeficiente de variação foi sempre inferior a $10 \%$ indicando baixa variação de Yp simulada ao longo dos 21 anos para uma mesma época de semeadura, sendo conseqüência da baixa variabilidade da temperatura e da radiação solar local ao longo dos anos analisados.

Para semeaduras entre $1 .^{\circ} / 1$ e $21 / 2$, correspondente ao cultivo "da seca", a produtividade real média (Yr) decresceu gradativamente de 1.590 para $958 \mathrm{~kg} \cdot \mathrm{ha}^{-1}$ à medida que se atrasou a semeadura (Quadro 2). Esses valores estão bem acima dos 746 kg.ha ${ }^{-1}$ obtidos na safra "da seca", em condições de campo, no Estado de Goiás (IBGE, 1999). Yr decresceu com o atraso da semeadura, em função do regime térmico e hídrico da região.
Fato semelhante foi constatado por RAmalHO et al. (1993) na região de Lavras, MG, em que a produtividade média de $1.959 \mathrm{~kg} \cdot \mathrm{ha}^{-1}$ da semeadura de fevereiro foi $21,5 \%$ superior à obtida em março.

Para a semeadura "de inverno" (entre 1. $/ 5 \mathrm{e}$ 21/6) é inviável o cultivo do feijoeiro sem irrigação, visto que não ocorrem chuvas significativas nesse período, impondo déficit hídrico durante todo o ciclo da cultura, resultando em produtividade real de 92 $\mathrm{kg} \cdot \mathrm{ha}^{-1}$, em média.

Uma vez que o problema nessa época de cultivo é a falta de precipitação pluvial, os dados do IBGE (1999) indicam que a cultura desenvolvida sob irrigação (safra 1998) resultou em produtividade acima de $2.400 \mathrm{~kg} \cdot \mathrm{ha}^{-1}$, em Goiás.

No caso de semeadura "das águas" (1. ${ }^{\circ} / 10$ a 21/11), Yr variou de 1.369 a 2.042 kg.ha ${ }^{-1}$, com média de $1.813 \mathrm{~kg} \cdot \mathrm{ha}^{-1}$. Esses valores são superiores ao rendimento médio de $1.667 \mathrm{~kg}$ ha $^{-1}$ obtido na safra 1998/ 99, no Estado de Goiás (IBGE, 1999). Se a semeadura fosse em dezembro a produtividade real simulada seria de $1.720 \mathrm{~kg} \cdot \mathrm{ha}^{-1}$, em média.

O ciclo da cultura, porém, abrangeria dezembro, janeiro, fevereiro, até meados de março, conforme as datas de semeadura $\left(1 .^{\circ} / 12,11 / 12\right.$ ou $\left.21 / 12\right)$ e, nesse período, concentram-se cerca de $60 \%$ do total anual das chuvas, fato que pode comprometer a produtividade, seja por doenças, seja pelo apodrecimento dos grãos no campo.

Evidencia-se a grande variabilidade de $\mathrm{Yr}$ simulada para as diferentes datas de semeadura, o que mostra sua sensibilidade às condições ambientais, principalmente às condições hídricas do solo. Essa sensibilidade do modelo pode ser confirmada pelos coeficientes de variação (CV, em \%) classificados entre médios a muito altos, indicando variabilidade nas estimativas ao longo dos 21 anos analisados. Os coeficientes de variação obtidos para a semeadura "da seca" e "de inverno" mostraram variações altas $(20 \%$ $\leq \mathrm{CV} \leq 30 \%)$ a muito altas $(\mathrm{CV}>30 \%)$ nas produtividades reais. Entretanto, para a semeadura das "águas" as variações de $\mathrm{Yr}$ foram médias $(10 \% \leq \mathrm{CV}<20 \%)$ a altas $(20 \% \leq \mathrm{CV}<30 \%)$. Essas variações podem ser atribuídas à distribuição irregular das precipitações pluviais.

Pela distribuição das freqüências de Yr simulada para Santo Antônio de Goiás (GO), cerca de 50\% dos valores ocorreram entre 0 a $600 \mathrm{~kg}$.ha ${ }^{-1}$, e cerca de $23 \%$ entre 1.201 e 1.800 kg.ha ${ }^{-1}$ (Figura 2). Essa distribuição enfatiza a distribuição da precipitação pluvial na região com predominância de suas ocorrências na primavera/verão e responsáveis pelos maiores valores de $\mathrm{Yr}$. 
Quadro 2. Produtividades reais médias e desvios padrões médios (DP) simulados pelo modelo CROPGRO - Dry Bean, e coeficientes de variação (CV), para a cultura do feijoeiro, cultivar Carioca, espaçamento de 0,60 m, em Santo Antônio de Goiás, (GO). Período de 1978 a 1998

\begin{tabular}{|c|c|c|c|c|c|c|c|}
\hline \multirow{2}{*}{ Semeadura } & \multicolumn{7}{|c|}{ Produtividade potencial (kg.ha $\left.{ }^{-1}\right)$} \\
\hline & Média & DP & $\mathrm{CV}$ & Semeadura & Média & $\mathrm{DP}$ & $\mathrm{CV}$ \\
\hline & & & $\%$ & & & & $\%$ \\
\hline $1 .^{\circ} / 01$ & 1.590 & 536 & 34 & $1 .^{\circ} / 07$ & 72 & 57 & 79 \\
\hline $11 / 01$ & 1.465 & 396 & 27 & $11 / 07$ & 111 & 78 & 71 \\
\hline $21 / 01$ & 1.488 & 371 & 25 & $21 / 07$ & 167 & 104 & 62 \\
\hline $1 .^{\circ} / 02$ & 1.327 & 345 & 26 & $1 .^{\circ} / 08$ & 320 & 297 & 93 \\
\hline $11 / 02$ & 1.060 & 451 & 43 & $11 / 08$ & 401 & 238 & 59 \\
\hline $21 / 02$ & 958 & 455 & 48 & $21 / 08$ & 646 & 349 & 54 \\
\hline $1 .^{\circ} / 03$ & 541 & 236 & 44 & $1 .^{\circ} / 09$ & 842 & 401 & 48 \\
\hline $11 / 03$ & 409 & 206 & 50 & $11 / 09$ & 1.075 & 336 & 31 \\
\hline $21 / 03$ & 215 & 76 & 35 & $21 / 09$ & 1.244 & 298 & 24 \\
\hline $1 .^{\circ} / 04$ & 174 & 63 & 36 & $1 .^{\circ} / 10$ & 1.369 & 251 & 18 \\
\hline $11 / 04$ & 143 & 33 & 23 & $11 / 10$ & 1.685 & 425 & 25 \\
\hline $21 / 04$ & 127 & 30 & 24 & $21 / 10$ & 1.814 & 415 & 23 \\
\hline $1 .^{\circ} / 05$ & 119 & 52 & 44 & $1 .^{\circ} / 11$ & 2.031 & 462 & 23 \\
\hline $11 / 05$ & 101 & 28 & 27 & $11 / 11$ & 1.937 & 471 & 24 \\
\hline $21 / 05$ & 84 & 44 & 52 & $21 / 11$ & 2.042 & 463 & 23 \\
\hline $1 .^{\circ} / 06$ & 81 & 48 & 60 & $1 .^{\circ} / 12$ & 1.743 & 424 & 24 \\
\hline $11 / 06$ & 93 & 68 & 73 & $11 / 12$ & 1.732 & 463 & 27 \\
\hline $21 / 06$ & 76 & 50 & 67 & $21 / 12$ & 1.685 & 447 & 27 \\
\hline
\end{tabular}

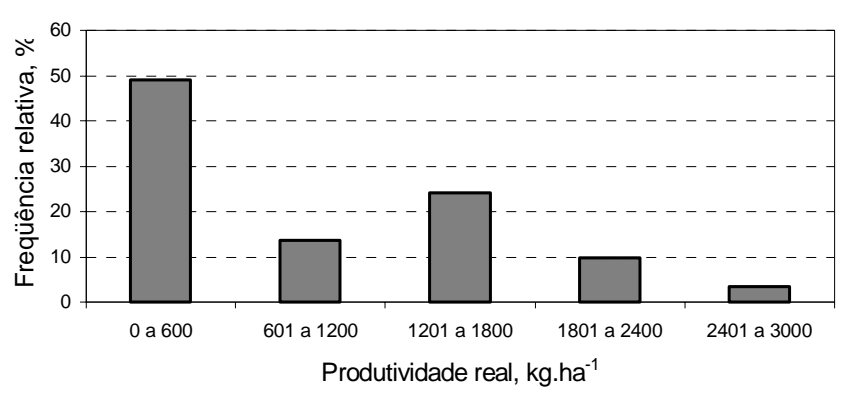

Figura 2. Distribuição de freqüência relativa da produtividade real simulada pelo modelo CROPGRO - Dry Bean, para a cultura do feijoeiro, cultivar Carioca, nas 36 datas de semeadura analisadas, em Santo Antônio de Goiás (GO). Período de 1978 a 1998.

Considerando-se a semeadura da "seca" (janeiro a fevereiro) percebe-se alto risco de quebra de produtividade já no primeiro decêndio de janeiro ultrapassando $50 \%$, e o risco de quebra vai aumentando gradativamente até o terceiro decêndio de fevereiro, quando então atinge 71\% (Figura 3).

$\mathrm{O}$ alto risco de quebra de produtividade está relacionado à ocorrência de veranicos, períodos de estiagem prolongada, variando de 7 a 20 dias, muito comuns nessa época do ano, e que causam a deficiência hídrica no solo. As taxas de quebra de rendimento aumentam consideravelmente, à medida que se atrasa a semeadura, atingindo riscos muito altos, acima de $95 \%$, principalmente, na semeadura de "inverno" (1. $\%$ a $21 / 6)$. Isso mostra a necessidade de se utilizar a irrigação durante todo o ciclo da cultura, na semeadura de "inverno", em decorrência da deficiência hídrica nesse período de estiagem. A maior quebra de rendimento (98\%) foi alcançada na semeadura de $1 .^{\circ} / 07$, ocorrendo posteriormente um declínio acentuado até a semeadura em $1 .^{\circ} / 10$, em torno de $53 \%$. Na semeadura das "águas", entre 11/10 e 21/ 11 , os menores riscos de quebra de produtividade foram em média de $34 \%$, corres-pondendo a um médio risco climático.

Sendo o feijoeiro uma cultura de alto risco climático, pode-se dizer que é conveniente que se faça irrigação suplementar nas semeaduras da "seca" e das "águas", e durante todo o ciclo, na semeadura de "inverno", na região de Santo Antônio de Goiás (GO).

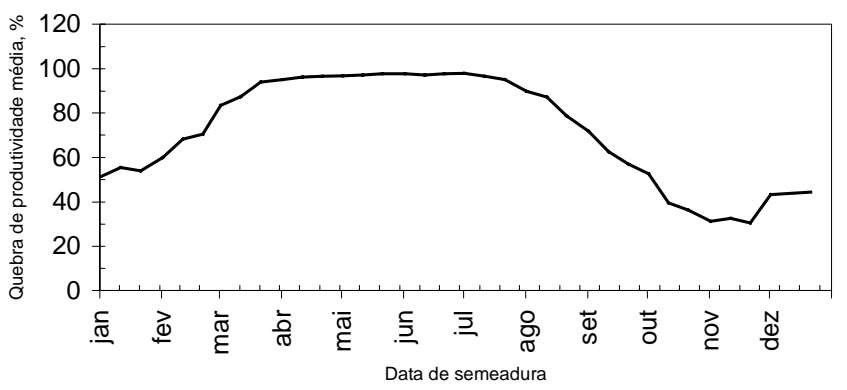

Figura 3. Variação anual da quebra relativa da produtividade média simulada pelo modelo CROPGRO - Dry Bean, para a cultura do feijoeiro, cultivar Carioca, nas 36 datas de semeadura analisadas, em Santo Antônio de Goiás (GO). Período de 1978 a 1998. 
MeIreles et al. (1997b), utilizando modelo de balanço hídrico (BIPZON) e Sistema de Informações Geográficas (SIG), verificaram que para uma cultivar de feijão de ciclo de 90 dias, e solo de baixa capacidade de armazenamento de água $(30 \mathrm{~mm})$, para semeadura realizada entre 6 e 10 de janeiro, as regiões situadas ao norte, noroeste e sudoeste do Estado de Goiás apresentaram condições de baixo risco climático. Entretanto, a partir do período de 16 a 20 de janeiro, praticamente, não houve regiões com baixo risco climático em todo o Estado de Goiás.

Aumentando-se a capacidade de armazenamento de água no solo para $50 \mathrm{~mm}$, verificou-se aumento expressivo de áreas de baixo risco climático, no período compreendido entre 6 e 30 de janeiro, comparando-se às situações anteriormente analisa- das. Situações de alto risco climático foram caracterizadas a partir de 6 e 10 de fevereiro. Assim, para a região de Santo Antônio de Goiás, o feijão da "seca", com semeaduras efetuadas entre 1 e 20 de janeiro, apresentou-se como de baixo risco climático, ou seja, favorável ao seu cultivo.

Porém, a partir do terceiro decêndio de janeiro, o risco passou de baixo para médio, e posteriormente, no primeiro decêndio de fevereiro, tornou-se uma região de alto risco climático, conforme os estudos de Silva et al. (1999). Apenas as semeaduras compreendidas entre $1 .^{\circ} / 11$ e $11 / 11$ apresentaram quedas de rendimento inferiores a $20 \%$, ocorrendo em 38\% dos casos (Quadro 3). Porém, em $48 \%$ dos casos foram verificadas quedas de rendimento entre $21 \%$ e $40 \%$ para a semeadura efetuada em $21 / 11$.

Quadro 3. Freqüência de quebra relativa de produtividade simulada pelo modelo CROPGRO - Dry Bean, para a cultura do feijoeiro, cultivar Carioca, espaçamento de 0,60 m, em Santo Antônio de Goiás (GO). Período de 1978 a 1998

\begin{tabular}{|c|c|c|c|c|c|}
\hline \multirow{2}{*}{ Semeadura } & \multicolumn{5}{|c|}{ Faixas de quebra relativa de rendimento } \\
\hline & 0 a 20 & 21 a 40 & 41 a 60 & 61 a 80 & 81 a 100 \\
\hline & & 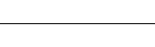 & - \% & . & \\
\hline $1 .^{\circ} / 01$ & 9,5 & 14,3 & 38,1 & 38,1 & 0,0 \\
\hline $11 / 01$ & 0,0 & 14,3 & 42,9 & 42,9 & 0,0 \\
\hline $21 / 01$ & 0,0 & 9,5 & 61,9 & 28,6 & 0,0 \\
\hline $1 .^{\circ} / 02$ & 0,0 & 4,8 & 52,4 & 38,1 & 4,8 \\
\hline $11 / 02$ & 0,0 & 4,8 & 23,8 & 52,4 & 19,0 \\
\hline $21 / 02$ & 0,0 & 0,0 & 23,8 & 52,4 & 23,8 \\
\hline $1 .^{\circ} / 03$ & 0,0 & 0,0 & 4,8 & 19,0 & 76,2 \\
\hline $11 / 03$ & 0,0 & 0,0 & 0,0 & 19,0 & 80,9 \\
\hline $21 / 03$ & 0,0 & 0,0 & 0,0 & 0,0 & 100,0 \\
\hline $1 .^{\circ} / 04$ & 0,0 & 0,0 & 0,0 & 0,0 & 100,0 \\
\hline $11 / 04$ & 0,0 & 0,0 & 0,0 & 0,0 & 100,0 \\
\hline $21 / 04$ & 0,0 & 0,0 & 0,0 & 0,0 & 100,0 \\
\hline $1 .^{\circ} / 05$ & 0,0 & 0,0 & 0,0 & 0,0 & 100,0 \\
\hline $11 / 05$ & 0,0 & 0,0 & 0,0 & 0,0 & 100,0 \\
\hline $21 / 05$ & 0,0 & 0,0 & 0,0 & 0,0 & 100,0 \\
\hline $1 .^{\circ} / 06$ & 0,0 & 0,0 & 0,0 & 0,0 & 100,0 \\
\hline $11 / 06$ & 0,0 & 0,0 & 0,0 & 0,0 & 100,0 \\
\hline $21 / 06$ & 0,0 & 0,0 & 0,0 & 0,0 & 100,0 \\
\hline $1 .^{\circ} / 07$ & 0,0 & 0,0 & 0,0 & 0,0 & 100,0 \\
\hline $11 / 07$ & 0,0 & 0,0 & 0,0 & 0,0 & 100,0 \\
\hline $21 / 07$ & 0,0 & 0,0 & 0,0 & 0,0 & 100,0 \\
\hline $01 / 08$ & 0,0 & 0,0 & 0,0 & 9,5 & 90,5 \\
\hline $1 .^{\circ} / 08$ & 0,0 & 0,0 & 4,8 & 4,8 & 90,5 \\
\hline $21 / 08$ & 0,0 & 0,0 & 9,5 & 47,6 & 42,9 \\
\hline $01 / 09$ & 0,0 & 0,0 & 28,6 & 33,3 & 38,1 \\
\hline $11 / 09$ & 0,0 & 0,0 & 47,6 & 47,6 & 4,8 \\
\hline $21 / 09$ & 0,0 & 4,8 & 57,2 & 33,3 & 4,8 \\
\hline $1 .^{\circ} / 10$ & 0,0 & 4,8 & 80,9 & 14,3 & 0,0 \\
\hline $11 / 10$ & 14,3 & 38,1 & 42,9 & 4,8 & 0,0 \\
\hline $21 / 10$ & 23,8 & 28,6 & 47,6 & 0,0 & 0,0 \\
\hline $1 .^{\circ} / 11$ & 38,1 & 23,40 & 38,1 & 0,0 & 0,0 \\
\hline $11 / 11$ & 38,1 & 19,0 & 38,1 & 4,8 & 0,0 \\
\hline $21 / 11$ & 28,6 & 47,6 & 23,8 & 0,0 & 0,0 \\
\hline $1 .^{\circ} / 12$ & 9,5 & 38,1 & 38,1 & 14,3 & 0,0 \\
\hline $11 / 12$ & 19,0 & 23,8 & 42,9 & 14,3 & 0,0 \\
\hline $21 / 12$ & 4,8 & 33,3 & 42,9 & 19,0 & 0,0 \\
\hline Média & 5,2 & 8,6 & 22,0 & 15,0 & 49,3 \\
\hline
\end{tabular}


Para a faixa de quebra relativa de rendimento entre $41 \%$ e $60 \%$, em média, $52 \%$ dos casos se concentraram entre $11 / 1$ e $1 .^{\circ} / 2$, e, que para $1 .^{\circ} / 10$ ocorreram $81 \%$ dos casos.

As quebras de rendimento superiores a $80 \%$ ocorreram sempre para as semeaduras de $21 / 3$ até $21 / 7$, coincidindo com a redução das chuvas e, conseqüentemente, da água disponível no solo.

Analisando-se a figura 4, que apresenta as freqüências de quebra relativa de produtividade da cultura do feijoeiro, referentes a todos os dados simulados, nota-se que, em apenas $5 \%$ dos casos, a quebra relativa foi abaixo de $20 \%$.

Em $49 \%$ dos casos ocorreram quebras de produtividade acima de $80 \%$, mostrando a sensibilidade do CROPGRO - Dry Bean aos efeitos da deficiência hídrica sobre a produtividade do feijoeiro.

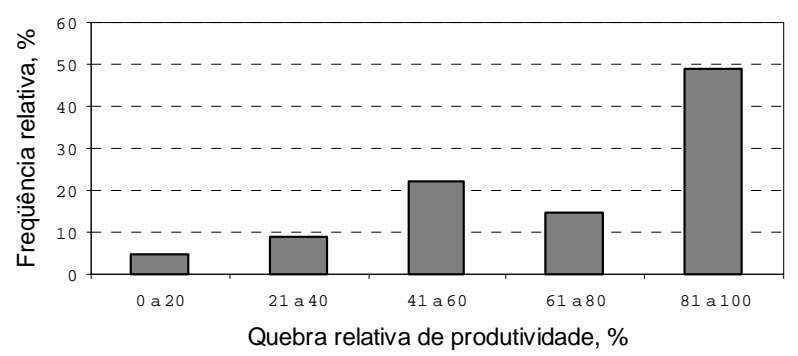

Figura 4. Distribuição de freqüência relativa das quebras relativas da produtividade simulada pelo modelo CROPGRO - Dry Bean, para a cultura do feijoeiro, cultivar Carioca, nas 36 datas de semeadura analisadas, em Santo Antônio de Goiás (GO). Período de 1978 a 1998.

\section{CONCLUSÕES}

1. Na região de Santo Antônio de Goiás, a época de semeadura para a cultura do feijoeiro com menor risco de quebra da produtividade é a das "águas" (outubro a novembro), com risco médio de $34 \%$. Nesta época, os menores riscos, abaixo de $20 \%$, ocorrem nas semeaduras entre o primeiro e o segundo decêndio de novembro.

2. Para a semeadura da "seca" (janeiro a fevereiro), o risco aumenta gradativamente do primeiro decêndio de janeiro (50\%) para o terceiro de fevereiro, quando atinge $71 \%$.

3. Para a época de "inverno" (maio a junho), o cultivo do feijoeiro só pode ser conduzido sob irrigação, pois os riscos são muito elevados, ultrapassando $95 \%$.

\section{REFERÊNCIAS BIBLIOGRÁFICAS}

EMPRESA BRASILEIRA DE PESQUISA AGROPECUÁRIA. Centro Nacional de Pesquisa de Arroz e Feijão. O cultivo do feijão: recomendações técnicas. Brasília: Embrapa, SPI, 1994. 83p. (Embrapa. CNPAF. Documentos, 48).

FANCELLI, A.L.; DOURADO NETO, D. Estresses de água e temperatura na cultura do feijão. In: FANCELLI, A.L.; DOURADO NETO, D. (Eds.) Feijão irrigado: estratégias básicas de manejo. Piracicaba: Publique, 1999. p.155-169.

FARIA, R.T. DE; FOLEGATTI, M.V.; FRIZZONE, J.A.; SAAD, A.M. Determination of a long-term optimal irrigation strategy for dry beans in Parana state, Brazil. Scientia Agricola, Piracicaba, v.54, p.155-164, 1997a. (Número especial)

FARIA, R.T. DE; OLIVEIRA, D. DE; FOLEGATTI, M.V. Simulação da fenologia e produção do feijoeiro pelo modelo BEANGRO. In: CONGRESSO BRASILEIRO DE AGROMETEOROLOGIA, 10., Piracicaba, 1997. Anais... Piracicaba: Sociedade Brasileira de Agrometeorologia, 1997b. p.141-142.

FARIAS, J.R.B.; ASSAD, E.D.; ALMEIDA, I.R. DE; EVANGELISTA, B.A.; SILVA, F.A.M DA; BEZERRA, H.S.; LAZZAROTTO, C. Identificação de regiões com riscos de déficit hídrico à cultura da soja. In: CONGRESSO BRASILEIRO DE AGROMETEOROLOGIA, 10., Piracicaba, 1997. Anais... Piracicaba: Sociedade Brasileira de Agrometeorologia, 1997. p.345-347.

HEINEMANN, A.B; HOOGENBOOM, G. Regional irrigation requirements for dry bean based on the simulation model CROPGRO and a geographic information system. Annual Report of the Bean Improvement Cooperative, East Lansing, v.44, p.41-42, 2001.

HOOGENBOOM, G.; JONES, J.W.; WILKENS, P.W.; BATCHELOR, W.D.; BOWEN, W.T.;HUNT, L.A.; PICKERING, N.B.; SINGH, U.; GODWIN, D.C.; BAER, B.; BOOTE, K.J.; RITCHIE, J.T.; WHITE, J.W. CROPGRO-DRY BEAN. In: TSUII, G.Y.; UEHARA, G.; BALAS, S. (Eds.). Crop models: DSSAT v 3. Honolulu: University of Hawaii, 1994. v.2, p.95-281.

INSTITUTO BRASILEIRO DE GEOGRAFIA E ESTATÍSTICA. Levantamento Sistemático da Produção Agrícola. Rio de Janeiro, v.3, n.6, 1991. n.p.

INSTITUTO BRASILEIRO DE GEOGRAFIA E ESTATÍSTICA. Levantamento Sistemático da Produção Agrícola. Rio de Janeiro, v.4, n.9, 1992. n.p.

INSTITUTO BRASILEIRO DE GEOGRAFIA E ESTATÍSTICA. Levantamento Sistemático da Produção Agrícola. Rio de Janeiro, v.5, n.10, 1993. n.p.

INSTITUTO BRASILEIRO DE GEOGRAFIA E ESTATÍSTICA. Levantamento Sistemático da Produção Agrícola. Rio de Janeiro, v.6, n.5, 1994. n.p.

INSTITUTO BRASILEIRO DE GEOGRAFIA E ESTATÍSTICA. Levantamento Sistemático da Produção Agrícola. Rio de Janeiro, v.7, n.5, 1995. n.p. 
INSTITUTO BRASILEIRO DE GEOGRAFIA E ESTATÍSTICA. Levantamento Sistemático da Produção Agrícola. Rio de Janeiro, v.8, n.12, 1996.

INSTITUTO BRASILEIRO DE GEOGRAFIA E ESTATÍSTICA. Levantamento Sistemático da Produção Agrícola. Rio de Janeiro, v.10, n.12, 1997. n.p.

INSTITUTO BRASILEIRO DE GEOGRAFIA E ESTATÍSTICA. Levantamento Sistemático da Produção Agrícola. Rio de Janeiro, v.11, n.12, 1998. n.p.

INSTITUTO BRASILEIRO DE GEOGRAFIA E ESTATÍSTICA. Levantamento Sistemático da Produção Agrícola. Rio de Janeiro, v.12, n.12, 1999. n.p.

INSTITUTO BRASILEIRO DE GEOGRAFIA E ESTATÍSTICA. Levantamento Sistemático da Produção Agrícola. Rio de Janeiro, v.12, n.12, 2000. n.p.

MARIN, F.R.; SENTELHAS, P.C.; UNGARO, M.R.G. Perda de rendimento potencial da cultura do girassol por deficiência hídrica, no Estado de São Paulo. Scientia Agricola, Piracicaba, v.57, n.1, p.1-6, 2000.

MEIRELES, E.J.L. Utilização do modelo CROPGRO - dry bean na análise de risco climático da cultura do feijoeiro (Phaseolus vulgaris L.) na região de cerrados. 2000. 105p. Tese (Doutorado) - Escola Superior de Agricultura "Luiz de Queiroz", Universidade de São Paulo, Piracicaba.

MEIRELES, E.J.L.; PEREIRA, A.R.; SENTELHAS, P.C.; STONE, L.F.; ZIMMERMANN, F.J.P. Aplicação do modelo CROPGRODry Bean na análise de risco climático na cultura do feijoeiro (Phaseolus vulgaris, L.) no cerrado goiano. In: CONGRESSO BRASILEIRODE AGROMETEOROLOGIA, 12., REUNIÃO LATINOAMERICANA DE AGROMETEOROLOGIA, 3., Fortaleza, 2001. Anais. Fortaleza: SBA/FUNCEME, v.2, 2001, p.537-538.

MEIRELES, E.J.L.; SILVA, S.C. DA; ASSAD, E.D.; LOBATO, E.J.V.; BEZERRA, H.S.; EVANGELISTA, B.A.; MOREIRA, L.; CUNHA, M.A.C. da. Zoneamento agroclimático para o arroz de sequeiro no Estado do Tocantins. Goiânia: EMBRAPA, CNPAF, APA, 1995. 72p . (EMBRAPA-CNPAF. Documentos, 58).

MEIRELES, E.J.L.; SILVA, S.C. DA; ASSAD, E.D.; XAVIER, L.S. Caracterização do risco climático na cultura do feijoeiro no Estado do Mato Grosso. In: CONGRESSO BRASILEIRO DE AGROMETEOROLOGIA, 10., Piracicaba, 1997. Anais... Piracicaba: Sociedade Brasileira de Agrometeorologia, 1997a. p.351-353.

MEIRELES, E.J.L.; SILVA, S.C. DA; ASSAD, E.D.; XAVIER, L.S. Estudo espaço-temporal do risco climático no feijoeiro, ciclo de 90 dias, em Goiás. In: CONGRESSO BRASILEIRO DE AGROMETEOROLOGIA, 10., Piracicaba, 1997b. Anais... Piracicaba: Sociedade Brasileira de Agrometeorologia, 1997b. p.348-350.

PORTER, C.H.; JONES, J.W.; BAER, B.; HOOGENBOOM, G.; RITCHIE, J.T.; PICKERING, N.B.; BOOTE, K.; CALMON, M.; BATCHELOR, W.D. Soil water balance module in CROPGRO v3.7 documentation and source code listing.. Gainesville: Agricultural and Biological Engineering Department, 1998. p.1-32. (Research Report, 98-503)
QUINTELA, E.D. Manejo integrado de pragas do feijoeiro no plantio de inverno. Santo Antônio de Goiás: Embrapa, 2000. 2p. (Pesquisa em Foco, 38)

RAMALHO, M.A.P.; ABREU, A.F.B.; RIGHETTO, G.U. Interação de cultivares de feijão por épocas de semeadura em diferentes localidades do Estado de Minas Gerais. Pesquisa Agropecuária Brasileira, Brasília, v.28, n.10, p.1183-1189, 1993.

RITCHIE, J.T. A user orientated model of the soil water balance in wheat. In: FRY, E.; ATKIN, T.K. (Eds.). Wheat growth and modeling. New York: NATO-ASI Ser., 1985. p.293-305.

ROLIM, G.S. Ajuste e comparação de modelos de simulação da produtividade para a determinação do risco climático da cultura do girassol (Helianthus annuus L.). 2000. 125p. Dissertação (Mestrado) - Escola Superior de Agricultura "Luiz de Queiroz", Universidade de São Paulo, Piracicaba.

SANS, L.M.A.; ASSAD, E.D.; AVELLAR, G.;FARIA, C.M.;SOUZA, L.F. Riscos climáticos para a cultura do milho nos Estados de Minas Gerais, Goiás, Tocantins, Mato Grosso e Mato Grosso do Sul. In: CONGRESSO BRASILEIRO DE AGROMETEOROLOGIA, 10., Piracicaba, 1997. Anais... Piracicaba: Sociedade Brasileira de Agrometeorologia, 1997. p.357-359.

SILVA, O.F.; BARBOSA FILHO, M.P. Adubação de cobertura com uréia: a alternativa mais econômica para a cultura do feijoeiro irrigado em sistema plantio direto. Santo Antônio de Goiás: Embrapa, 2000. 2p. (Pesquisa em Foco, 39)

SILVA, S.C. DA; MEIRELES, E.J.L., ASSAD, E.D.; XAVIER, L.S.; CUNHA, M.A.C. Caracterização do risco climático para o arroz de terras altas no Estado do Mato Grosso. Goiânia: Embrapa, CNPAF, 1997. 72p. (Embrapa. CNPAF. Documentos, 76).

SILVA, S.C.;MEIRELES, E.J.L.; XAVIER, L.S.; ALVES, S.F.; BARSI, R.O. Zoneamento agroclimático para o cultivo do feijão da "seca" em Goiás. Santo Antônio de Goiás: Embrapa Arroz e Feijão, 1999. 52p. (Embrapa Arroz e Feijão. Documentos, 94).

STONE, L.F.; PEREIRA, A.L. Sucessão arroz -feijão irrigados por aspersão: efeitos de espaçamento entre linhas, adubação e cultivar no crescimento, desenvolvimento radicular e consumo d'água do feijoeiro. Pesquisa Agropecuária Brasileira, Brasília, v.29, n.6, p.939-954, 1994a.

STONE, L.F.; PEREIRA, A.L. Sucessão arroz -feijão irrigados por aspersão: efeitos de espaçamento entre linhas, adubação e cultivares na produtividade e nutrição do feijoeiro. Pesquisa Agropecuária Brasileira, Brasília, v.29, n.4, p.521-533, 1994b.

WHITE, J.W.; IZQUIERDO, J. Physiology of yield potential and stress tolerance. In: SCHOONHOVEN, A. van; VOYSEST, O. (Eds.). Common beans: research for crop improvement. Cali: CIAT, 1991. p.287-382.

WREGE, M.S.; GONÇALVES, S.L.; CARAMORI, P.H.; VASCONCELOS, M.E.C.; OLIVEIRA, D.; ABUCARUB NETO, M.; CAVIGLIONE, J.H. Risco de deficiência hídrica na cultura do feijoeiro durante a safra das águas no Estado do Paraná. Revista Brasileira de Agrometeorologia, Santa Maria, v.5, n.1, p.51-59, 1997. 